\title{
SÍNTESE DE NANOPARTÍCULAS DE GELATINA POR DESSOLVATAÇÃO EM DOIS PASSOS PARA APLICAÇÃO EM TERAPIA FOTODINÂMICA
}

\author{
Janicy Arantes Carvalho ${ }^{1}$ \\ Caroline Ribeiro de Melo ${ }^{2}$ \\ Alexandro da Silva Abreu ${ }^{3}$ \\ Leandro José Raniero ${ }^{4}$ \\ Milton Beltrame Junior ${ }^{5}$ \\ Andreza Ribeiro Simioni ${ }^{6}$
}

Resumo: A Terapia Fotodinâmica é utilizada no tratamento de doenças oncológicas e não oncológicas. Sua ação depende da retenção de um fármaco fotossensível nas células alvos e posterior irradiação com luz visível. Dentre os fármacos utilizados podemos citar as ftalocianinas, um composto eficiente em gerar oxigênio singlete, porém com baixa solubilidade em meios aquosos. Este problema pode ser minimizado por meio dos sistemas de liberação controlada de fármacos (DDS). Neste trabalho foi realizada a incorporação da Cloro Ftalocianina de Alumínio em nanopartículas de gelatina (NPG) visando um novo DDS. Os resultados obtidos mostraram que as NPG apresentaram tamanho uniforme e morfologia esférica. A partir das análises espectroscópicas verificou-se que a incorporação do fármaco não alterou o perfil espectral do composto. Neste trabalho sintetizou-se com sucesso um novo DDS que apresentou as propriedades desejadas e características específicas destes sistemas.

Palavras-chave: Nanotecnologia; Ftalocianina; Gelatina; Terapia Fotodinâmica.

\footnotetext{
${ }^{1}$ Laboratório de Síntese Orgânica, Instituto de Pesquisa e Desenvolvimento-IP\&D/Universidade do Vale do Paraíba, Brasil. E-mail: janicyjun@gmail.com.

2 Laboratório de Síntese Orgânica, Instituto de Pesquisa e Desenvolvimento-IP\&D/Universidade do Vale do Paraíba, Brasil. E-mail: carolinermelo7@gmail.com.

${ }^{3}$ Laboratório de Síntese Orgânica, Instituto de Pesquisa e Desenvolvimento-IP\&D/Universidade do Vale do Paraíba, Brasil. E-mail: alexandrosilvaabreu@gmail.com.

${ }^{4}$ Laboratório de Nanossensores, Instituto de Pesquisa e Desenvolvimento-IP\&D/Universidade do Vale do Paraíba, Brasil. E-mail: Iraniero@univap.br.

${ }_{5}^{5}$ Laboratório de Síntese Orgânica, Instituto de Pesquisa e Desenvolvimento-IP\&D/Universidade do Vale do Paraíba, Brasil. E-mail: beltrame@univap.br.

${ }^{6}$ Laboratório de Síntese Orgânica, Instituto de Pesquisa e Desenvolvimento-IP\&D/Universidade do Vale do Paraíba, Brasil. E-mail: simioni@univap.br.
} 